\title{
Inhaled insulin: overview of a novel route of insulin administration
}

\author{
This article was published in the following Dove Press journal: \\ Vascular Health and Risk Management \\ 13 January 2010 \\ Number of times this article has been viewed
}

\section{Lucy D Mastrandrea}

Department of Pediatrics, School of Medicine and Biochemical Sciences, University at Buffalo, Buffalo, NY, USA

Correspondence: Lucy D Mastrandrea Women and Children's Hospital of Buffalo, 219 Bryant Street, Buffalo, NY 14222, USA

$\mathrm{Tel}+\mathrm{I}(7 \mathrm{I} 6)$ 878-7588

Fax +I (7I6) 888-3827

Email Idm@buffalo.edu
Abstract: Diabetes is a chronic disease characterized by inadequate insulin secretion with resulting hyperglycemia. Diabetes complications include both microvascular and macrovascular disease, both of which are affected by optimal diabetes control. Many individuals with diabetes rely on subcutaneous insulin administration by injection or continuous infusion to control glucose levels. Novel routes of insulin administration are an area of interest in the diabetes field, given that insulin injection therapy is burdensome for many patients. This review will discuss pulmonary delivery of insulin via inhalation. The safety of inhaled insulin as well as the efficacy in comparison to subcutaneous insulin in the various populations with diabetes are covered. In addition, the experience and pitfalls that face the development and marketing of inhaled insulin are discussed.

Keywords: glycemic control, hemoglobin $\mathrm{A}_{1 \mathrm{c}}$, inhalation, insulin, type 1 diabetes, type 2 diabetes

\section{Introduction}

Diabetes is a class of diseases characterized by elevated blood sugar in the face of inadequate insulin production or insulin action. The disease affects approximately 23.6 million Americans ( $8 \%$ of the population), and fully one-third of those individuals are unaware that they have the disease. ${ }^{1}$ There are two broad categories of diabetes - type 1 (T1DM) and type 2 diabetes (T2DM). Individuals with T1DM are dependent on insulin for survival and rely on subcutaneous administration by injection or continuous infusion. Patients with T2DM may control their disease for a time with lifestyle intervention or oral therapies. However, those who fail these strategies will require insulin to achieve adequate disease control. Delivery of insulin via inhalation is a potential alternative to subcutaneous insulin in the management of diabetes. This review will discuss the rationale for development of pulmonary delivered versions of insulin as well as discuss the role that inhaled insulin may play in improving long-term diabetes care.

\section{Rationale for intensified diabetes care}

Associations between hyperglycemia and the long-term complications of diabetes have been demonstrated both in animal models and human studies. Elevated glucose levels lead to significant vascular endothelial cell dysfunction, contributing to morbidities associated with the disease. ${ }^{2}$ Individuals with diabetes are at risk for both microvascular disease including nephropathy, retinopathy, and neuropathy and macrovascular disease including both fatal and nonfatal myocardial infarction and stroke. Epidemiologic studies have demonstrated a correlation between diabetes and cardiovascular disease. 
The diagnosis of T2DM increases the risk of coronary heart disease by a factor of 2 - to 4 -fold, ${ }^{3}$ while those with T1DM have about a 10-fold increase in cardiovascular disease compared to age-matched individuals without diabetes. ${ }^{4,5}$ Large prospective trials, such as the Diabetes Control and Complications Trial (DCCT, T1DM) ${ }^{6}$ and the United Kingdom Prospective Diabetes Study (UKPDS, T2DM), ${ }^{7}$ have demonstrated that improving metabolic control, as measured by mean glycosylated hemoglobin $\left(\mathrm{HbA}_{1 \mathrm{c}}\right)$, decreases the risk of microvascular complications. Declines in $\mathrm{HbA}_{1 \mathrm{c}}$ correlate with reductions in both the development and progression of diabetic retinopathy, nephropathy, and neuropathy, indicating that addressing hyperglycemia is relevant even in those with established complications. These large trials did not show declines in macrovascular disease with improved blood sugar control. However, in the Epidemiology of Diabetes Interventions and Complications Trial (EDIC), a follow-up of the DCCT, patients who had received intensified therapy for a period of 6.5 years had a $42 \%$ decrease in the risk of a first cardiovascular event compared to the conventionally treated group. ${ }^{6}$ More recent studies have called into question the goal of striving for near-normal glycemic control $\left(\mathrm{HbA}_{1 \mathrm{c}}<6 \%\right)$ in the T2DM population because of increased risk of cardiovascular death. Current recommendations in diabetes care are to aim for as close to euglycemia as possible.

While intensive therapy is recognized as a means to improve long-term outcomes for patients with diabetes, fewer than $40 \%$ of patients achieve the glycemic targets set forth by the American Diabetes Association (ADA) and American Association of Clinical Endocrinologists (AACE). Barriers to achieving these goals are multi-factorial and include failure of patients to accept intensified therapies and inability of current regimens to mimic physiologic insulin delivery.

Intensive therapy in T1DM involves multiple daily subcutaneous injections of insulin (3 to 5 per day) usually with long-acting insulin as basal insulin and short-acting insulin administered just prior to meals. Alternatively, continuous subcutaneous insulin infusion (CSII) pumps can be used. For individuals with T2DM, initial management includes lifestyle interventions such as diet and exercise. However, most patients will eventually require oral therapies that stimulate pancreatic $\beta$-cell insulin secretion (secretagogues) or improve insulin sensitivity (biguanides or thiazolidinediones). If glycemic goals are not met, insulin therapy must be initiated. For patients with diabetes, either intensifying (T1DM) or adding (T2DM) insulin therapy can be challenging. Patients often resist transitioning to insulin injections out of fear and concern about the skill sets needed to correlate carbohydrate intake with insulin administration. ${ }^{8}$ Because of these concerns, intensification of insulin therapy to improve metabolic control is often delayed, and adherence to injection regimens may be suboptimal.

Secretion of insulin in response to carbohydrate intake is tightly regulated. ${ }^{9}$ Insulin is released into the portal venous system to exert effects at the liver initially, suppressing glycogenolysis and gluconeogenisis before acting peripherally to stimulate glucose uptake and inhibit lipolyis. ${ }^{10}$ Current strategies of subcutaneous insulin administration do not mimic this first-pass effect of insulin on hepatic glucose control. Thus, particularly for fasting/basal glucose control, subcutaneous therapy fails to restore intra-portal insulin concentrations resulting in inappropriate hepatic glucose output. Attempts to address this therapeutic concern by increasing doses of basal insulin may place the patient at risk for hypoglycemia, particularly in the fasting state. While available insulin analogs provide improved coverage of meal-time glucose excursions, timing of insulin administration and careful attention to matching carbohydrate ingestion with insulin dose is paramount to limit post-prandial hyperglycemia.

Therapies aimed at addressing these concerns include oral insulin (intestinal absorption and buccal mucosal absorption), implantable peritoneal insulin pumps, and inhaled insulin. While enteral insulin therapy is limited by enzymatic degradation, there are ongoing trials to assess the feasibility of oral spray insulin in the treatment of T1DM compared to twice daily insulin injections (www.clinicaltrials.gov identifier NCT00668850). ${ }^{11}$ A recent study demonstrated that compared to traditional CSII, patients using the implantable peritoneal insulin pump had reduced $\mathrm{HbA}_{1 \mathrm{c}}$ with more time spent in the euglyemic range and less time in the hyperglycemic range. However, this option may be limited by cost and does carry the risk of peritoneal infections and implantation site complications. ${ }^{12}$ Finally, pulmonary delivery of insulin, which was first tested in $1924,{ }^{13,14}$ has been an area of active investigation and development.

\section{The lung as a vehicle for drug adminstration}

Pulmonary delivery of drugs is used extensively in the treatment of respiratory diseases such as asthma, chronic obstructive pulmonary disease (COPD), and cystic fibrosis. Treatment goals for these disorders are to deliver drugs locally to affect bronchospasm ( $\beta$-agonists), inflammation (inhaled steroids), and local bacterial infection (antibiotics), while limiting systemic effects. The distal lung provides a large surface area $\left(145 \mathrm{~m}^{2}\right)$ with a thin $(0.2 \mu \mathrm{M})$ 
alveolar epithelium allowing for absorption of particles into the bloodstream for systemic action. ${ }^{15}$ Factors which influence the distribution of drugs to the distal lung include particle size, particle speed, and ventilatory parameters. In order for particles to be deposited in the alveolar space, their size should be between 1 and $3 \mu \mathrm{M}$; smaller particles are exhaled and particles $>5 \mu \mathrm{M}$ are deposited in the upper airways or swallowed. ${ }^{16}$ Patient cooperation and appropriate ventilator technique are important to ensure reproducible delivery of drug to the deep lung. Inhalers that allow for release of the insulin particles at the start of a deep, slow inhalation provide the best penetration to the alveolar space. ${ }^{17,18}$ Rapid shallow inhalations lead to significant losses of the drug in the oropharynx and upper airways. Thus, ability to perform appropriate breathing maneuvers plays an important role in maximizing the effectiveness of inhaled insulin therapy.

\section{Development of inhaled insulin}

Shortly after Banting and Best discovered insulin in the early $1920 \mathrm{~s},{ }^{19}$ the first studies using inhaled insulin were performed. In these studies, it was reported that blood glucose decreased in response to inhalation of insulin. ${ }^{14,20}$ In 1987, it was demonstrated that nebulized human insulin provided blood sugar control comparable to subcutaneous insulin in 6 children with T1DM. ${ }^{21}$ However, it was recognized that the bioavailability of inhaled insulin was significantly lower than that of subcutaneous preparations. Consequently, it was not until the development of improved delivery devices and understanding of particle pharmacology that inhaled insulin became ready for clinical study.

\section{Inhaled insulin devices}

Devices capable of delivering particulate insulin to the alveolar space have been developed and studied in a variety of clinical protocols. The ideal device should not only deliver insulin in a consistent fashion in order to achieve optimal glycemic control, but also should be convenient for patients - both portable and user-friendly. Over the course of the last 20 years, several companies have worked to develop inhaled insulin systems for patient use. The systems differ in the formulation of the inhaled insulin - liquid vs lyophilized powder - and the delivery device with respect to size, mechanism of insulin release, and regulation of insulin administration (mechanical vs electronic). The bioavailability of inhaled insulin for each of the devices varies, but is in the range of $10 \%$ to $46 \%$, with much of the drug being lost within the device or in the oropharynx or upper airways. ${ }^{22}$ Table 1 summarizes the features of inhaled insulin delivery systems that have been studied most extensively.

Exubera $^{\circledR}$ was developed through a collaboration between Nektar Therapeutics and Pfizer and, in 2006, was approved by the Food and Drug Association (FDA) and the European Medicines Agency (EMEA) for treatment of both T1DM and T2DM. The insulin delivered by this device is a dry powder formulation packaged in blister packets containing $1 \mathrm{mg}$ or $3 \mathrm{mg}$ of regular human insulin. The unit doses are delivered via a mechanical inhaler and are equivalent to 3 units and 8 units of subcutaneously delivered short-acting insulin, respectively. Much of the medical literature describing the pharmacokinetics, glucodynamics, and safety profiles of inhaled insulin was obtained from studies using Exubera ${ }^{\circledR}$. However, in October 2007, Pfizer announced that it would no longer be selling Exubera ${ }^{\circledR}$ secondary to poor sales and acceptance.

The AERx insulin diabetes management system $\left(\mathrm{AERx}^{\circledR}\right.$ iDMS) was developed by both Aradigm Corporation and Novo Nordisk. This system creates an aerosol of insulin droplets from a liquid insulin preparation. The device has

Table I Inhaled insulin systems

\begin{tabular}{|c|c|c|c|c|c|c|c|}
\hline $\begin{array}{l}\text { Inhalation } \\
\text { system }\end{array}$ & $\begin{array}{l}\text { Insulin } \\
\text { formulation }\end{array}$ & Insulin equivalents ${ }^{a}$ & $\begin{array}{l}\text { Inhaler } \\
\text { device }\end{array}$ & $\begin{array}{l}\text { Method of } \\
\text { inhalation }\end{array}$ & Device Size $^{b}$ & Device benefits & Current status \\
\hline Exubera $^{\circledR}$ & $\begin{array}{l}\text { Dry powder, } \\
\text { blisters }\end{array}$ & $\begin{array}{l}\mathrm{Img}=3 \mathrm{U} \\
3 \mathrm{mg}=8 \mathrm{U}\end{array}$ & Mechanical & User dependent & $20 \mathrm{~cm} \times 4 \mathrm{~cm}$ & Collapsible & $\begin{array}{l}\text { FDA-approved } \\
\text { off-market }\end{array}$ \\
\hline AERx iDMS ${ }^{\circledR}$ & $\begin{array}{l}\text { Liquid insulin, } \\
\text { blisters }\end{array}$ & $\mathrm{I}$ AERx unit $=\mathrm{I} U$ & Electronic & Guided system & $8 \mathrm{~cm} \times 4 \mathrm{~cm}$ & Download capability & $\begin{array}{l}\text { No further } \\
\text { development }\end{array}$ \\
\hline $\mathrm{AIR}^{\circledR}$ & $\begin{array}{l}\text { Dry powder, } \\
\text { capsules }\end{array}$ & $\begin{array}{l}6 \mathrm{mg}=2 \mathrm{U} \\
9 \mathrm{mg}=6 \mathrm{U}\end{array}$ & Mechanical & Breath actuated & $7 \mathrm{~cm} \times 2 \mathrm{~cm}$ & Small device size & $\begin{array}{l}\text { No further } \\
\text { development }\end{array}$ \\
\hline Technosphere $^{\circledR}$ & $\begin{array}{l}\text { Dry powder } \\
\text { microspheres, } \\
\text { cartridges }\end{array}$ & $\begin{array}{l}6 \mathrm{TU}=1.56 \mathrm{U} \\
12 \mathrm{TU}=3.12 \mathrm{U} \\
24 \mathrm{TU}=6.24 \mathrm{U}\end{array}$ & Mechanical & User dependent & $10 \mathrm{~cm} \times 5 \mathrm{~cm}$ & Placebo formulation & $\begin{array}{l}\text { Phase } 3 \text { trials } \\
\text { FDA - new drug } \\
\text { application }\end{array}$ \\
\hline
\end{tabular}

${ }^{a}$ Compared to regular insulin; bapproximate size. Abbreviation: TU, technosphere units. 
electronic controls that guide the user to inhale the insulin in a reproducible fashion. In addition, the device offers the capability to download dosing, use frequency, and inhalation patterns to aid the prescriber and patient in monitoring adherence and treatment goals. Although the AERx ${ }^{\circledR}$ system was in phase III trials, Novo Nordisk elected to discontinue further study with this system given the experience of Pfizer with Exubera ${ }^{\circledR}$.

$\mathrm{AIR}^{\circledR}$ insulin system, developed in conjunction with Eli Lilly and Co. and Alkermes Inc. uses a dry powder insulin with a mechanical inhaler. The inhaled particles are significantly larger ( 5 to $30 \mu \mathrm{M}$ ), yet less dense than those of other systems, and are delivered efficiently to the alveolar space. While this system has been through extensive phase III testing, Eli Lilly and partners are not pursuing development of this product at present.

The Technosphere ${ }^{\circledR}$ system combines a dry powder recombinant human insulin (Mannkind Corp.) with the MedTone ${ }^{\circledR}$ inhaler (Pharmaceutical Discovery Corp.). This system is currently in phase III trials and is unique in that the partners have developed a placebo formulation for inhalation, allowing for design of double-blind, placebo controlled studies in patients with T2DM. ${ }^{23}$ Technosphere ${ }^{\circledR}$ compares favorably to regular insulin administrated subcutaneously in controlling postprandial hyperglycemia, suggesting that this formulation may provide improved blood sugar control. ${ }^{24}$

While there are other inhaled insulin devices/systems that have been developed, much of the investigation in this area has been halted. A review of www.clinicaltrials.gov using inhaled insulin as a key word revealed 75 trials, 20 of which were terminated before projected completion dates. Only 5 trials of inhaled insulin are listed as either actively recruiting or not yet recruiting, 4 of which are investigating Technosphere ${ }^{\circledR}$ insulin. ${ }^{25}$ Mannkind has filed a new drug application with the FDA; it remains to be seen whether this application will be approved. ${ }^{26}$

\section{Pharmacology of inhaled insulin}

Discussion of the pharmacology of inhaled insulin involves both the study of pharmacokinetics - measurement of serum insulin levels following administration of the drug - and pharmacodynamics - measurement of onset and duration of hypoglycemic effect. Most of the inhaled insulin devices are designed to be used in conjunction with carbohydrate consumption, targeting control of prandial glucose excursions. The ideal system would closely mimic $\beta$-cell secretion of insulin with rapid onset of action followed by sustained activity over a period of $2-3$ hours to control rising glucose concentrations while limiting delayed hypoglycemic effects. The majority of studies compare different inhaled insulin delivery systems to regular insulin administered subcutaneously which has a peak effect on glycemia 30-60 minutes after administration and duration of action up to four hours.

\section{Pharmacokinetics of inhaled insulin}

Studies to assess serum concentrations of insulin following inhalation have been performed in healthy volunteers as well individuals with both T1DM and T2DM. A summary of the pharmokinetic parameters for various inhaled insulin devices is provided by Patton et al. ${ }^{22}$ In a comparison of Exubera ${ }^{\circledR}$ and regular insulin in healthy nonsmoking males, the total insulin exposure was similar for inhaled insulin and regular insulin. ${ }^{27}$ However, the time to maximal insulin concentration $\left(\mathrm{C}_{\max }\right)$ was more rapid for inhaled insulin vs regular insulin (55 min vs $148 \mathrm{~min}$ ). In an open-label 4-way crossover study in healthy volunteers comparing 3 different Technosphere ${ }^{\circledR}$ inhaled insulin doses and regular insulin, similar results were found $-\mathrm{C}_{\max }$ was 12 to 17 min for Technosphere insulin and 134 min for regular insulin. ${ }^{28}$ Studies performed with the $\mathrm{AERx}^{\circledR}$ system in patients with T1DM also revealed there was a more rapid rise in serum insulin in the inhaled group vs regular insulin group. ${ }^{29}$ However, the intrasubject variability with respect to total insulin exposure was $\sim 26 \%$ for the inhaled group, indicating that consistent inhalation techniques could play a significant role in diabetes control. Rave et al compared Technosphere ${ }^{\circledR}$ insulin to regular insulin in 16 patients with T2DM. ${ }^{24} \mathrm{C}_{\max }$ was reached earlier (15 min vs $120 \mathrm{~min}$ ) and was $45 \%$ greater for inhaled insulin compared to regular insulin. In addition, while the total insulin exposure for inhaled insulin was comparable to that of subcutaneous insulin, the exposure time was shorter with inhaled insulin, suggesting that the risk of delayed hypoglycemia may be less with the inhaled insulin formulation. ${ }^{24}$

\section{Glucodynamics of inhaled insulin}

Glucodynamics is measured by determining the infusion rate of glucose necessary to maintain euglycemia following the administration of insulin. This parameter determines the hypoglycemic effect of therapy. In healthy males receiving inhaled insulin, rates of glucose infusion were higher in the first hour after dosing than in those receiving regular insulin by injection, correlating with the more rapid rise in serum insulin levels. ${ }^{27}$ This maximal effect on glycemia is comparable to short-acting insulin analogs. Total glucose consumption was comparable for bioequivalent doses of 
inhaled vs regular insulin over the entire clamp period. ${ }^{27}$ In individuals with T1DM, the glucose infusion rate profile showed an early peak rate with inhaled insulin $\left(\mathrm{AERx}^{\circledR}\right)$ vs regular insulin with a similar glucose consumption. ${ }^{29}$ Rave et al performed mixed-meal tolerance tests in 16 individuals with T2DM and compared the ability of Technosphere ${ }^{\circledR}$ insulin and regular insulin to control postprandial glucose levels. Both maximal postprandial glucose excursion and total blood glucose area under the curve were significantly lower following use of inhaled insulin in this group, indicating that for similar insulin exposure, glycemic control was improved with inhaled insulin. ${ }^{24}$ The rapid onset of action coupled with the ability to exert an effect on glucose levels for several hours after administration, makes inhaled insulin a good candidate for control of meal-time glucose levels.

Bioavailability of inhaled insulin is limited by several factors including losses of the drug within the inhalation device, oropharynx, or upper airways, as well as adequate ventilatory maneuvers to deposit insulin to the lower airways. ${ }^{22}$ In studies using the $\mathrm{AERx}^{\circledR}$ device in individuals with T1DM, it was estimated that the system efficiency on a unit/kilogram basis was $13 \%$ as measured by glucodynamics compared to injected regular insulin. ${ }^{29}$ This indicates that more insulin is needed for inhalation therapy compared to injection, a factor which could play a role in risk of long-term side effects as well as cost of therapy.

\section{Equivalence dosing of inhaled insulin}

Pharmacokinetic and glucodynamic studies have been performed to determine the equivalence of each inhaled insulin formulation relative to subcutaneous insulin. ${ }^{30,31}$ These results are summarized in Table 1. In order for patients to receive the appropriate amount of insulin to cover carbohydrate ingestion, they must perform a series of inhalations using the doses available for each delivery system. For example, a patient normally requiring 10 units of regular insulin could inhale either three $1 \mathrm{mg}$ blisters (9 unit equivalents) or one $1 \mathrm{mg}$ blister and one $3 \mathrm{mg}$ blister (11 unit equivalents) of Exubera ${ }^{\circledR}$ to achieve a comparable insulin dose. A study was performed in healthy nonsmoking adults to determine whether different dose combinations of $\mathrm{AIR}^{\circledR}$ capsules were interchangeable. ${ }^{32}$ The pharmacokinetic and glucodynamic results demonstrated that combinations of different $\mathrm{AIR}^{\circledR}$ capsule dose strengths were equivalent. Thus, there is greater flexibility with insulin dosing as well as less glycemic variability when equivalent dose strengths are interchanged in this system.

\section{Use of inhaled insulin in treatment of diabetes}

Multiple studies have been performed in patients with both T1 and T2DM to assess the efficacy of inhaled insulin in controlling diabetes. Inhaled insulin has been compared to regular insulin or short-acting insulin analogs in patients with T1DM. Studies including individuals with T2DM have assessed the effect of inhaled insulin on diabetes control when added to oral therapy as well as in comparison to short-acting insulin. Outcome measures have included $\mathrm{HbA}_{1 \mathrm{c}}$, pulmonary function, weight gain, and patient satisfaction. ${ }^{33}$

\section{Type I diabetes}

Current strategies to control blood glucose levels in individuals with T1DM involve subcutaneous insulin injections given multiple times per day (2 to 5) or insulin pump therapy via CSII. In patients receiving injection therapy, they generally receive long-acting (basal) insulin 1 or 2 times/day and short-acting insulin with meals to cover post-prandial meal excursions. Multiple daily injection therapy places a burden on patients and is a significant barrier to optimizing adherence to diabetes regimens aimed at improving glycemic control. Inhaled insulin has the potential to replace shortacting insulin analogs, eliminating as many as 4 injections per day.

Inhaled insulin administered before meals has been compared in a randomized controlled fashion to regimens using regular insulin preprandially and either NPH (twice daily) or ultralente (once daily). In studies performed using Exubera $^{\circledR}$, inhaled insulin was noninferior with respect to $\mathrm{HbA}_{1 \mathrm{c}}$ changes, although 2-hour postprandial and fasting plasma glucose levels were lower in the groups receiving inhaled insulin. ${ }^{34,35}$ In a recent study reported by Garg et al 385 individuals with T1DM were randomized to receive either inhaled insulin $\left(\mathrm{AIR}^{\circledR}\right)$ or regular/lispro insulin before meals with glargine serving as the basal insulin. ${ }^{36}$ After 2 years of study, only $20 \%$ of study subjects reached a target $\mathrm{HbA}_{1 \mathrm{c}}$ of $<7 \%$, and inhaled insulin was demonstrated to be inferior to preprandial subcutaneous insulin with respect to change in $\mathrm{HbA}_{1 \mathrm{c}}$. When individuals with T1DM were treated with glargine as basal insulin and randomized to either Technosphere ${ }^{\circledR}$ inhaled insulin or rapid acting insulin analog, both groups had comparable decreases in $\mathrm{HbA}_{1 \mathrm{c}}$ at 1 year; however, the inhaled insulin group had significantly lower fasting plasma glucose and 1 hour postprandial glucose levels compared to those on subcutaneous insulin. ${ }^{37}$ The discrepancies between the studies related to effects of inhaled insulin on $\mathrm{HbA}_{1 \mathrm{c}}$ may be related either to the 
inhaled insulin formulation itself or to the basal insulin used in each study.

\section{Type 2 diabetes}

Individuals with T2DM often have complicated medication regimens when the addition of insulin is considered. Patients may be taking several different classes of drugs in an effort to control blood sugars - oral hypoglycemic agents (sulfonylureas or meglitinides) and insulin sensitizers (biguanides or thiazolidindiones). Rosenstock et al performed a trial in T2DM patients on dual oral agent therapy who continued to have poor glycemic control $\left(\mathrm{HbA}_{1 \mathrm{c}}>8 \%\right)$. Patients were randomized to continued oral therapy, oral therapy plus Exubera $^{\circledR}$, or Exubera ${ }^{\circledR}$ alone. $\mathrm{HbA}_{1 \mathrm{c}}$ improved by $1.4 \%$ (inhaled) and 1.9\% (inhaled plus oral agents) compared to oral agents alone. ${ }^{38}$ This suggests that some patients may achieve adequate glycemic control on inhaled insulin alone, thereby simplifying their treatment regimen. In addition, individuals randomized to inhaled insulin plus oral agents had a greater likelihood of reaching glycemic targets compared to those on oral agents alone ( $32 \%$ vs $1 \%){ }^{38}$

As discussed above, Mannkind Corporation has developed a placebo based device for use in clinical trials as a comparator to Technosphere ${ }^{\circledR}$ inhaled insulin. This controls for the attention received by subjects within a study as well as the motivation factor ascribed to subjects who are randomized to inhaled insulin, in contrast to subcutaneous insulin, that may bias study outcomes. Individuals with T2DM suboptimally controlled on oral agents were randomized in a double-blind fashion to receive either placebo Technosphere ${ }^{\circledR}$ powder or Technosphere ${ }^{\circledR}$ insulin before meals. ${ }^{23}$ Use of inhaled insulin resulted in a significant decline in $\mathrm{HbA}_{1 \mathrm{c}}$ compared to those using placebo, taking into consideration that $\mathrm{HbA}_{1 \mathrm{c}}$ was mildly elevated in all subjects at baseline $(8 \%$, inhaled insulin group; $7.8 \%$ placebo group).

In a study of patients with T2DM on insulin therapy, subjects received either pre-meal Exubera ${ }^{\circledR}$ plus ultralente (subcutaneous) or twice daily injections of regular and NPH insulin. ${ }^{39}$ There was no difference in the reduction in $\mathrm{HbA}_{1 \mathrm{c}}$ between the groups, although those randomized to inhaled insulin were more likely to achieve $\mathrm{HbA}_{1 \mathrm{c}}<7 \%$ (odds ratio $2.27,95 \%$ confidence interval 1.24 to 4.14 ). In a similar population of patients with T2DM, AERx ${ }^{\circledR}$ premeal inhaled insulin was compared to premeal subcutaneous regular insulin, both in combination with bedtime NPH insulin. ${ }^{40}$ After 12 weeks of therapy, there was no difference in $\mathrm{HbA}_{1 \mathrm{c}}$ between the two groups, and both groups experienced a similar decline in $\mathrm{HbA}_{1 \mathrm{c}}$ from baseline
( $-0.69 \%$ vs $-0.77 \%$; inhaled vs subcutaneous). A further study in individuals with poorly controlled T2DM receiving oral therapy plus basal glargine demonstrated that the addition of $\mathrm{AIR}^{\circledR}$ inhaled insulin to once-daily glargine resulted in a greater improvement in $\mathrm{HbA}_{1 \mathrm{c}}(-0.97 \%$ vs $-0.62 \%$; inhaled + glargine vs glargine), even when glargine dose was titrated to optimize glycemic control. ${ }^{41}$ Individuals with T2DM initially randomized to either inhaled or subcutaneous insulin in a 12-week proof of concept study were offered the option of continuing inhaled insulin for 1 year. ${ }^{30}$ In those who elected to continue inhaled insulin, the decrease in $\mathrm{HbA}_{1 \mathrm{c}}(-0.78 \%)$ was sustained throughout the extension trial, indicating that the therapeutic effects on glycemic control are durable. ${ }^{42}$ It should be noted that, thus far, no clinical trial has demonstrated that inhaled insulin is superior to subcutaneous insulin for the goal of diabetes care - improved glycemic control.

\section{Special populations}

\section{Smoking and inhaled insulin}

It is estimated that $20 \%$ to $25 \%$ of individuals with diabetes are tobacco smokers. ${ }^{43}$ Smoking induces both acute and chronic effects on the pulmonary system, including vasoconstriction, changes in permeability, and remodeling of the bronchioalveolar lining. Therefore, efforts have been made to address the effects that smoking has on the pharmacokinetics of inhaled insulin. Following administration of inhaled insulin, nondiabetic chronic smokers have a higher $\mathrm{C}_{\max }$, greater absorption of insulin $\left(\mathrm{AUC}_{0-360}\right)$, and shorter time to $\mathrm{C}_{\max }$ nonsmokers. ${ }^{44,45}$ These data suggest that individuals who smoke would be at higher risk for hypoglycemia when treated with inhaled insulin. Becker et al examined the effects of smoking cessation on pharmacokinetics of inhaled insulin. ${ }^{46}$ Within 1 week of smoking cessation, the $\mathrm{C}_{\max }$ and $\mathrm{AUC}_{0-360}$ after inhaled insulin had decreased significantly and approached that of nonsmokers. Resumption of smoking reversed the effects of smoking cessation, with both insulin exposure and glucose utilization increasing. However, tobacco use is also associated with insulin-resistance, ${ }^{47}$ and Wise et al demonstrated that although nondiabetic smokers had a greater exposure to insulin following inhalation compared to nonsmokers, they did not have increased glucose utilization as measured by glucose infusion rates. ${ }^{44}$ Therefore, particularly in the T2DM population, the increase in alveolar permeability that leads to increased insulin absorption following inhalation may be counteracted by the effects of insulin resistance mediated both by the disease state and smoking. 
In contrast to chronic smoking, individuals who are exposed to passive smoking have a different response to inhaled insulin. In healthy nonsmokers, exposure to cigarette smoke for 2 hours prior to insulin inhalation resulted in significantly lower insulin bioavailability and pharmacokinetic parameters. ${ }^{48}$ This is similar to the effect of acute cigarette smoking just prior to insulin inhalation by smokers, where the $\mathrm{AUC}_{0-360}$ is not increased. ${ }^{45}$ Thus, smoking, whether acute or chronic, passive or primary, impacts the pharmacokinetics of inhaled insulin, placing patients at risk for fluctuations in blood sugars with resulting suboptimal metabolic control.

When inhaled insulin was on the market, it was not approved for smokers or for those who had smoked within the previous 6 months. Given the fact that Pfizer and Nektar Pharmaceuticals announced an increase in lung cancer cases in former smokers involved in clinical trials of Exubera ${ }^{\circledR}$, it is unlikely that any inhaled insulin that comes to market in the future will be approved for either smokers or previous smokers. ${ }^{49}$

\section{Respiratory disease and inhaled insulin}

Because both acute and chronic respiratory diseases have the potential to alter the pharmacodynamic effects of inhaled insulin, it is necessary to understand how illness and pulmonary pathology influence inhaled insulin action. Acute respiratory illnesses are a common occurrence and are accompanied by cough, mucous production, and inflammation of the pulmonary tree. In nondiabetic adults, there was no difference in the pharmacokinetics or glucose response to inhaled insulin either during the acute or recovery phase of an upper respiratory tract infection. ${ }^{50}$ In addition, pulmonary function tests (PFTs) following administration of inhaled insulin were unchanged in the same subjects. These observations suggest inhaled insulin is efficacious even in the clinical setting of acute upper respiratory infection. Comparable studies have not been performed in subjects recovering from lower respiratory tract infections such as pneumonia.

Asthma is a chronic disease characterized by inflammation and airway hyper-reactivity with periods of exacerbation and quiescence. In order for inhaled insulin to be recommended in this population, it must not trigger bronchospasm, and it must be provide optimal blood sugar control during acute asthma exacerbations. In a study of non-diabetic subjects with mild to moderate asthma, it was demonstrated that compared to healthy subjects, the overall exposure to insulin (AUC) was $34 \%$ to $41 \%$ less. ${ }^{51}$ The glucodynamic effects of inhaled insulin were comparable between healthy and subjects with mild asthma, while the ability of inhaled insulin to lower serum glucose was decreased in subjects with moderate asthma. This effect was ameliorated by pretreating subjects with a long-acting $\beta$-agonist to alleviate airway narrowing. There were no acute asthma exacerbations as a result of insulin inhalation. ${ }^{51}$

The prevalence of diabetes in patients with COPD is as high as $12 \% .^{52}$ This disease is categorized as being both restrictive (emphysema) and obstructive (chronic bronchitis) in its effects on pulmonary function. These complications may limit the ability of individuals to use the inhalation devices appropriately or may restrict the surface area available for insulin absorption across the alveolar membrane. Rave et al performed a randomized cross-over study comparing the responses to inhaled vs subcutaneous short-acting insulin in both healthy controls (nonsmokers) and individuals with COPD who had not smoked for longer than 6 months. ${ }^{53}$ They demonstrated that while inhaled insulin was well tolerated in those with chronic lung disease, serum levels of immunoreactive insulin following inhaled insulin administration were lower in individuals with COPD, particularly in those with chronic bronchitis compared to control subjects. The insulin effect in patients with COPD was $60 \%$ to $65 \%$ of the control subjects. Thus, for those with COPD, increased doses of inhaled insulin may be necessary to achieve the same degree of metabolic control. There were no acute effects on pulmonary function in response to insulin inhalation. ${ }^{53}$

\section{Age and inhaled insulin}

Both lung volumes and diffusion capacity change as a function of age. ${ }^{54}$ These changes can modulate both delivery of inhaled insulin to the distal airways, as well as absorption of the insulin across the alveolar epithelium. Henry et al demonstrated that in individuals with T2DM, increasing age ( $>65$ years) impacted the ability of inhaled insulin to lower glucose levels compared to a younger population (age 18 to 45 years) while $\mathrm{C}_{\max }$ and $\mathrm{AUC}_{0-360}$ were not different between the two groups. ${ }^{55}$ These results indicate that, in older patients, an increased inhaled insulin dose may be required to achieve comparable diabetes control.

\section{Adverse effects}

The adverse effects of inhaled insulin are summarized in Table 2 . There have been no adverse effects uniquely associated with a specific insulin formulation or delivery device. 
Table 2 Side effects of inhaled insulin formulations

\begin{tabular}{lll}
\hline Side effect & Degree of effect $^{\mathrm{a}}$ & Notes \\
\hline Cough & + & Coincident with inhalation, decreased severity over time. Occasionally treatment limiting. \\
Change in FEV & +- & FEV, testing required by FDA prior to initiation of therapy. \\
Change in DLCO & + & Decline early in treatment then stable. Reversal of effect upon discontinuation of therapy. \\
Insulin antibodies & + & $\begin{array}{l}\text { Increased titers compared to subcutaneous formulations. No correlation with pharmacologic effect. } \\
\text { Hypoglycemia }\end{array}$ Less risk of severe hypoglycemia compared to subcutaneous insulin. Increased risk in insulin naïve $^{\text {patients. }}$ \\
Weight gain & $+/-$ & $\begin{array}{l}\text { Associated with addition of any insulin to therapeutic regimen in T2DM. Weight neutral to decrease } \\
\text { in TIDM. }\end{array}$ \\
\hline
\end{tabular}

Notes: aDegree to which effect was observed when reported by investigators; +, effect consistently observed; +/-, effect inconsistently observed.

Abbreviations: $\mathrm{DL}_{\mathrm{CO}}$, carbon monoxide diffusion capacity; $\mathrm{FEV}_{1}$, forced expiratory volume in I second.

\section{Body weight}

One concern with insulin therapy is that, with intensified protocols, weight tends to increase. This is particularly true for patients with T2DM, in whom excess weight gain contributes to worsening insulin resistance, with corresponding need for increased insulin doses. In studies enrolling patients with T1DM, there was either no change ${ }^{56}$ or a trend towards less weight gain $^{35,37}$ in those receiving inhaled insulin vs subcutaneous short-acting insulin analog. In a study of insulin-naïve patients with T2DM, inhaled insulin monotherapy or in conjunction with 2 oral agents resulted in a mean $2.7 \mathrm{~kg}$ weight gain compared to oral agent therapy.$^{38}$ However, in individuals with T2DM previously receiving subcutaneous insulin therapy, there was no weight change in those treated with inhaled insulin vs those continued on subcutaneous insulin therapy. ${ }^{30}$ All individuals who transition to intensified diabetes care should be counseled about the risk of weight gain, regardless of the therapeutic regimen.

\section{Hypoglycemia}

Treatment strategies aimed at achieving euglycemia carry the risk of increased number and severity of hypoglycemic events. ${ }^{6}$ Inhaled insulin is associated similar rates of hypoglycemia when compared to subcutaneous insulin in both $\mathrm{T} 1$ and T2DM populations; no increase in severity of episodes was reported..$^{30,35,56}$ In a study including subjects with T2DM on oral agent therapy alone prior to study entrance, the incidence of hypoglycemic events was greater in the cohorts receiving inhaled insulin compared to oral agents alone ( $66 \%$ to $76 \%$ vs $8 \%) .{ }^{38}$ In addition, the rates of symptoms associated with hypoglycemia, including tremor, sweating, and headache were higher in the inhaled insulin groups. However, the rate of severe hypoglycemic events, defined as an event requiring outside assistance, was not increased. ${ }^{38}$

\section{Pulmonary function}

Given that insulin therapy will be life-long for many diabetics, it is relevant to understand the effects that inhaled insulin has on lung function. There are hypothetical concerns about the toxicity of insulin particulates on the alveolarcapillary network as well as the growth-promoting effects of insulin when it binds competitively, albeit at significantly lower potency, to insulin growth factor-1 receptors in the lung. ${ }^{22}$ Rosenstock et al demonstrated no changes in either forced expiratory volume at 1 second $\left(\mathrm{FEV}_{1}\right)$, total lung capacity, or carbon monoxide diffusion capacity $\left(\mathrm{DL}_{\mathrm{CO}}\right)$ in patients with T2DM receiving inhaled insulin for a period of 12 weeks. ${ }^{38} \mathrm{~A} 2$-year follow-up study in patients with T2DM treated with inhaled insulin as an adjunct to oral therapies demonstrated that there was a decrease in $\mathrm{FEV}_{1}$ and $\mathrm{DL}_{\mathrm{CO}}$ at 24 weeks of therapy that did not progress throughout the course of the study. ${ }^{57}$ Interestingly, the oral therapy group also showed similar declines during the course of the study, although the change in $\mathrm{FEV}_{1}$ was slightly greater in the inhaled insulin group. These findings are comparable to previous studies measuring the annual rate of change in $\mathrm{FEV}_{1}$ in a group of individuals with $\mathrm{T} 2 \mathrm{DM},{ }^{58}$ suggesting that the declines do not reflect adverse effects of the drug, but, rather, represent the natural history of the disease with respect to lung function.

Short-term (6-month) studies in patients with T1DM have demonstrated that $\mathrm{DL}_{\mathrm{CO}}$ decreases by $\sim 0.75$ to $1.2 \mathrm{~mL} / \mathrm{min} /$ $\mathrm{mm} \mathrm{Hg.}{ }^{34,35}$ Long-term study of the effects of inhaled insulin on lung function in patients with T1DM is limited to a 4-year extension trial combining patients with both $\mathrm{T} 1$ and T2DM. Annualized changes in $\mathrm{FEV}_{1}$ were $-0.057 \pm 0.004$ $\mathrm{L} /$ year in the inhaled insulin group and $-0.071 \pm 0.023 \mathrm{~L} /$ year in the control group, while $\mathrm{DL}_{\mathrm{CO}}$ changes were $-0.376 \pm$ $0.067 \mathrm{~mL} / \mathrm{min} / \mathrm{mmHg}$ and $-0.673 \pm 0.423 \mathrm{~mL} / \mathrm{min} / \mathrm{mmHg}$, respectively. ${ }^{59}$ Although these experiences suggest that 
inhaled insulin is safe with respect to lung function, when Exubera ${ }^{\circledR}$ was on the market, it was recommended that all patients have $\mathrm{FEV}_{1}$ tested at baseline, after 6 months of therapy, and annually while taking the drug. For individuals with $\mathrm{FEV}_{1}<70 \%$ predicted or a decline $\geq 20 \%$, it was recommended that the drug be discontinued. Longer-term studies will help to determine whether the effects of inhaled insulin on pulmonary function have clinical repercussions.

Mild to moderate cough occurs more frequently in individuals receiving inhaled insulin. Coughing episodes were usually reported coincident with insulin inhalation. $.^{23} \mathrm{How}-$ ever, both the rate and severity of this effect decreased over time in studies reporting this outcome..$^{34,35,38}$ No differences in cough rates were observed in subjects using Technosphere inhaled insulin vs Technosphere ${ }^{\circledR}$ placebo powder. ${ }^{23}$ In addition, cough was not a significant contributor to subject withdrawal from clinical studies.

\section{Insulin antibodies}

The delivery of insulin whether subcutaneously, intraperitoneally, or by inhalation leads to the formation of circulating insulin immunoglobulins. ${ }^{60-62}$ High circulating levels of insulin antibodies may disrupt glycemic control by 2 mechanisms. First, the antibodies may bind to the insulin blocking its action with resulting hyperglycemia. ${ }^{63,64}$ Secondly, the insulin may then be released from the antibody complex, with inappropriate insulin action (discordant with carbohydrate intake) and delayed hypoglycemia. ${ }^{65,66}$ In rare cases, true insulin allergies may develop. ${ }^{62}$

The experience with inhaled insulin has not unearthed these concerns. In patients with both T1DM and T2DM, levels of insulin antibodies were measured following the introduction and use of inhaled insulin. Individuals with T1DM using inhaled insulin had a $22 \%$ increase in the median percentage antibody binding compared to those treated with CSII therapy. ${ }^{67}$ For patients with T2DM, the use of inhaled insulin led to the development of insulin antibodies. The peak levels were significantly lower than those observed in patients with T1DM, and peak antibody levels were reached within 6 to 12 months of inhaled insulin exposure. Insulin antibody levels increased in all groups treated with inhaled insulin; there was no association of antibodies with hypo/hyperglycemia, deterioration of metabolic control, allergic reactions, or changes in pulmonary function testing. Thus, while the delivery of insulin to the pulmonary system induces immune responses, these have not been demonstrated to decrease the effectiveness of inhaled insulin over time. ${ }^{68}$

\section{Quality of life and adherence to therapy}

One of the proposed benefits to inhaled insulin therapy is that, in contrast to injections, it will be accepted more readily by patients when insulin therapy must be intensified or when oral therapy is failing to achieve glycemic goals. Freemantle et al demonstrated that the availability of inhaled insulin as a hypothetical treatment option increases the likelihood that patients with poorly controlled T2DM will accept the addition of insulin to their therapeutic regimen. ${ }^{69}$ Alternatively, Bergenstal et al addressed the question of whether having the opportunity to choose $\mathrm{AIR}^{\circledR}$ insulin increased the likelihood that individuals with poorly controlled T2DM would choose any insulin therapy. ${ }^{70}$ In this study, subjects were randomized to receive counseling on therapeutic options to intensify diabetes management that either excluded or included inhaled insulin. The study determined that the availability of inhaled insulin did not increase the likelihood that individuals would add insulin to their treatment regimen. In addition, both groups had a comparable improvement in $\mathrm{HbA}_{1 \mathrm{c}}$ regardless of whether they added inhaled or subcutaneous insulin. ${ }^{70}$ Finally, patients with T1DM who received Exubera ${ }^{\circledR}$ reported higher overall satisfaction scores and quality of life scores compared to those receiving subcutaneous therapy. ${ }^{35}$ Rosenstock et al reported that, following a 12-week randomized controlled trial comparing inhaled and subcutaneous insulin, $85 \%$ of patients randomized to inhaled insulin elected to continue the drug, and $75 \%$ of those randomized to subcutaneous therapy elected to switch to inhaled insulin. In addition, overall satisfaction with inhaled insulin therapy was sustained for 1 year of therapy and impacted psychological well-being in a positive manner. ${ }^{42}$ This is an important finding given that the glycemic control in these patients was comparable to that of subcutaneous insulin and did not deteriorate throughout the extension phase of the study, ${ }^{42}$ suggesting that adherence to inhaled insulin therapy remained high.

Adherence is the measure that a patient is taking medications as prescribed by their provider. Rates of adherence are lowest in chronic diseases, and decline with increases in daily dosing. ${ }^{71}$ Claxton et al showed that with four times/day medication schedule, the rate of adherence was less than $50 \% .^{72}$ Individuals with diabetes often have multiple medical problems, necessitating polypharmacy with complicated dosing schedules. Therefore, any delivery system improving adherence in the diabetic population would be welcome. Measuring adherence to subcutaneous insulin therapy via syringe is difficult; proxy outcomes are number of prescriptions filled, vials of insulin used, and difference in $\mathrm{HbA}_{1 \mathrm{c}}$ 
following initiation of therapy. The $\mathrm{AERx}^{\circledR}$ system records the date and time of each insulin administration as well as the adequacy of the inhalation technique. Rates of adherence to preprandial insulin administration were as high as $95 \%$ in a group of patients with T2DM using the AERx ${ }^{\circledR}$ system, and $97 \%$ of patients received less than 5 inadequate doses during the treatment period studied..$^{73}$ Thus, this inhaled insulin system may serve as a useful tool to aid in acceptance of insulin and improvement of glycemic control.

\section{Cost of inhaled insulin}

The cost of inhaled insulin is significantly higher than that of subcutaneous insulin since more drug must be inhaled in order to achieve comparable glycemic control. However, a substantial driving force for the development of inhaled insulin has focused on the concept that availability of alternate insulin delivery systems will increase the likelihood that those with diabetes will adhere to their treatment regimens. In particular, those with T2DM may be more willing to start insulin when inhaled insulin is available as an option. ${ }^{69}$ Adherence and intensified diabetes care would translate into improved diabetes outcomes, particularly for decreased rates of micro- and macrovascular complications. Thus, the cost-effectiveness of inhaled insulin for quality of life and downstream clinical benefits can be considered when evaluating the economics of inhaled insulin.

Black et al performed an extensive analysis of the cost and cost-effectiveness of Exubera ${ }^{\circledR}$ in patients with T2DM. ${ }^{74}$ They determined that the addition of Exubera ${ }^{\circledR}$ to a regimen which included 2 oral agents was US\$1669/year more than adding basal glargine. Using a model to calculate costeffectiveness assuming that inhaled insulin would improve quality of life and glycemic control over the lifetime of the patient, the authors determined that, while quality of life cost-savings of US\$110 to US\$220 per patient might be realized over 20 years of therapy, this was significantly outweighed by the excess cost compared to basal subcutaneous therapy - US\$14,000 to US\$20,700. Given that inhaled insulin is not superior to subcutaneous therapy with respect to glycemic control, there would have to be additional direct patient benefits to improve cost-effectiveness. These analyses will be considered by third party payers when making decisions on reimbursement for inhaled insulin.

\section{Conclusions}

Several important issues remain with respect to the likelihood that inhaled insulin will be used clinically in the future. The first is the significant impact that the launch and subsequent withdrawal of Exubera ${ }^{\circledR}$ from the market had on the continued study and development of competing inhaled insulin devices. The second major development is the report from Pfizer that there is an increased incidence of lung cancer among former smokers who were treated with Exubera ${ }^{\circledR} .{ }^{49}$ As a consequence of this revelation, it is likely that the FDA will limit the use of inhaled insulin to individuals who have never smoked and require extensive postmarketing studies to address issues related to carcinogenicity risk. Finally, with the continued development of devices that have improved the ability to deliver subcutaneous insulin, including insulin pumps and insulin pens, the niche in the diabetes market which inhaled insulin is likely to occupy may be limited. Although the concept of inhaled insulin is attractive, the availability of subcutaneous insulin regimens that provide intensive diabetes care and the concern about pulmonary function and health will significantly affect future development in this area.

In conclusion, inhaled insulin is a novel route of insulin administration which has the potential to become a therapeutic option in the treatment of both T1DM and T2DM. Overall, clinical trials have demonstrated that inhaled insulin is noninferior to subcutaneous insulin for improving glycemic control. In addition, inhaled insulin serves as relevant adjuvant therapy in individuals with T2DM suboptimally controlled on oral therapy. The most notable advantage of inhaled insulin over subcutaneous insulin therapy is that it is well accepted by patients and improves overall satisfaction scores. Thus, availability of inhaled insulin may translate to improved diabetes control and decrease the risk of long-term diabetes complications.

\section{Disclosure}

The author declares no conflicts of interest.

\section{References}

1. Centers for Disease Control and Prevention. National diabetes fact sheet: general information and national estimates on diabetes in the United States. 2007. Atlanta, GA: US Department of Health and Human Services, Centers for Disease Control and Prevention, 2008. URL. http://www.cdc.gov/diabetes/pubs/factsheet07.htm. Accessed August 26, 2009.

2. Bakker W, Eringa EC, Sipkema P, vanHinsbergh VW. Endothelial dysfunction and diabetes: roles of hyperglycemia, impaired insulin signaling and obesity. Cell Tissue Res. 2009;335(1):165-189.

3. Stamler J, Vaccaro O, Neaton JD, Wentworth D. Diabetes, other risk factors, and 12-yr cardiovascular mortality for men screened in the Multiple Risk Factor Intervention Trial. Diabetes Care. 1993;16(2):434-444.

4. Krolewski AS, Kosinski EJ, Warram JH, et al. Magnitude and determinants of coronary artery disease in juvenile-onset, insulin-dependent diabetes mellitus. Am J Cardiol. 1987;59(8):750-755.

5. Laing SP, Swerdlow AJ, Slater SD, et al. Mortality from heart disease in a cohort of 23,000 patients with insulin-treated diabetes. Diabetologia. 2003;46(6):760-765. 
6. The Diabetes Control and Complications Trial Research Group. The effect of intensive treatment of diabetes on the development and progression of long-term complications in insulin-dependent diabetes mellitus. N Engl J Med. 1993;329(14):977-986.

7. UK Prospective Diabetes Study (UKPDS) Group. Intensive bloodglucose control with sulphonylureas or insulin compared with conventional treatment and risk of complications in patients with type 2 diabetes (UKPDS 33). Lancet. 1998;352(9131):837-853.

8. Zambanini A, Newson RB, Maisey M, Feher MD. Injection related anxiety in insulin-treated diabetes. Diabetes Res Clin Pract. 1999;46(3): 239-246.

9. Prentki M, Matschinsky FM. Ca2+, cAMP, and phospholipid-derived messengers in coupling mechanisms of insulin secretion. Physiol Rev. 1987;67(4):1185-1248.

10. Porte D, Sherwin R, Baron A. Ellenberg and Rifkin's Diabetes Mellitus. 6th ed. New York: McGraw-Hill. 2003:43-65.

11. ClincalTrials.gov. [homepage on the Internet]. A service of the US National Institutes of Health. [updated October 13, 2009]. URL: http:// clinicaltrials.gov/ct2/show/NCT00668850. Accessed October 14, 2009.

12. Logtenberg SJ, Kleefstra N, Houweling ST, et al. Improved glycemic control with intraperitoneal versus subcutaneous insulin in type 1 diabetes:a randomized controlled trial. Diabetes Care. 2009;32(8):1372-1377.

13. Laqueur E, Grevenstuk A. Uber die wirkunk intratrachealer zuführung von insulin. Klin Wochenschr. 1924;3:1273-1274.

14. Gänsslen M. Uber inhalation von insulin. Klin Wochenschr. 1925;4:71.

15. Patton JS, Byron PR. Inhaling medicines: delivering drugs to the body through the lungs. Nat Rev Drug Discov. 2007;6(1):67-74.

16. Usmani OS, Biddiscombe MF, Barnes PJ. Regional lung deposition and bronchodilator response as a function of beta2-agonist particle size. Am J Respir Crit Care Med. 2005;172(12):1497-1504.

17. Katz IM, Schroeter JD, Martonen TB. Factors affecting the deposition of aerosolized insulin. Diabetes Technol Ther. 2001;3(3):387-397.

18. Farr SJ, McElduff A, Mather LE, et al. Pulmonary insulin administration using the AERx system: physiological and physiochemical factors influencing insulin effectiveness in healthy fasting subjects. Diabetes Technol Ther. 2000;2(2):185-197.

19. Bliss M. The Discovery of Insulin. Chicago, IL: University of Chicago Press; 1982.

20. Heubner W, de Jongh S, Laquer E. Uber inhalation von insulin. Klin Wochenschr. 1924;3:2342-2343.

21. Elliott RB, Edgar BW, Pilcher CC, Quested C, McMaster J. Parenteral absorption of insulin from the lung in diabetic children. Aust Paediatr J. 1987;23(5):293-297

22. Patton JS, Bukar JG, Eldon MA. Clinical pharmacokinetics and pharmacodynamics of inhaled insulin. Clin Pharmacokinet. 2004;43(12):781-801.

23. Rosenstock J, Bergenstal R, DeFronzo RA, et al. Efficacy and safety of Technosphere inhaled insulin compared with Technosphere powder placebo in insulin-naive type 2 diabetes suboptimally controlled with oral agents. Diabetes Care. 2008;31(11):2177-2182.

24. Rave K, Heise T, Pfutzner A, Boss AH. Coverage of postprandial blood glucose excursions with inhaled Technosphere insulin in comparison to subcutaneously injected regular human insulin in subjects with type 2 diabetes. Diabetes Care. 2007;30(9):2307-2308.

25. ClincalTrials.gov. [homepage on the Internet]. A service of the US National Institutes of Health. URL: www.ClinicalTrials.gov/ct2/ results?term=inhaled+insulin. Accessed September 23, 2009.

26. Garg SK, Kelly WC. Insulin delivery via lungs - is it still possible? Diabetes Technol Ther. 2009;11(Suppl 2):S1-S3.

27. Rave K, Bott S, Heinemann L, et al. Time-action profile of inhaled insulin in comparison with subcutaneously injected insulin lispro and regular human insulin. Diabetes Care. 2005;28(5):1077-1082.

28. Rave K, Potocka E, Boss AH, Marino M, Costello D, Chen R. Pharmacokinetics and linear exposure of AFRESA compared with the subcutaneous injection of regular human insulin. Diabetes Obes Metab. 2009;11(7):715-720.
29. Brunner GA, Balent B, Ellmerer M, et al. Dose-response relation of liquid aerosol inhaled insulin in Type 1 diabetic patients. Diabetologia. 2001;44(3):305-308.

30. Cefalu WT, Skyler JS, Kourides IA, et al. Inhaled human insulin treatment in patients with type 2 diabetes mellitus. Ann Intern Med. 2001;134(3):203-207.

31. Rave K, Nosek L, De la Pena A, et al. Dose response of inhaled drypowder insulin and dose equivalence to subcutaneous insulin lispro. Diabetes Care. 2005;28:2400-2405.

32. de la Pena A, Seger M, Rave K, Heinemann L, Silverman B, Muchmore DB. AIR insulin capsules of different dose strengths may be combined to yield equivalent pharmacokinetics and glucodynamics. Diabetes Technol Ther. 2009;11(S2):S75-S79.

33. Royle P, Waugh L, McAuley L, McIntyre L, Thomas S. Inhaled insulin in diabetes mellitus. Cochrane Database Syst. Rev. 2004;CD003890.

34. Skyler JS, Weinstock RS, Raskin P, et al. Use of inhaled insulin in a basal/bolus insulin regimen in type 1 diabetic subjects. Diabetes Care. 2005;28(7):1630-1635.

35. Quattrin T, Belanger A, Bohannon NJV, Schwartz SL. Efficacy and safety of inhaled insulin (Exubera) compared with subcutaneous insulin therapy in patients with type 1 diabetes. Diabetes Care. 2004;27(11):2622-2627

36. Garg SK, Mathieu C, Rais N, et al. Two-year efficacy and safety of AIR inhaled insulin in patients with type 1 diabetes: An open-label randomized controlled trial. Diabetes Technol Ther. 2009;11(S2):S5-S16.

37. Bergenstal RM, Kapsner PL, Rendell MS, et al. Comparative efficacy and safety of AFRESA and a rapid-acting analog both given with glargine in subjects with T1DM in a 52-week study. Diabetes. 2009:A479.

38. Rosenstock J, Zinman B, Murphy LJ, et al. Inhaled insulin improves glycemic control when substituted for or added to oral combination therapy in type 2 diabetes: a randomized, controlled trial. Ann Intern Med. 2005;143(8):549-558.

39. Hollander PA, Blonde L, Rowe R, et al. Efficacy and safety of inhaled insulin (Exubera) compared with subcutaneous insulin therapy in patients with type 2 diabetes. Diabetes Care. 2004;27(10):2356-2362.

40. Hermansen K, Rönnemaa T, Petersen AH, Bellaire S, Adamson U. Intensive therapy with inhaled insulin via the AERx insulin diabetes management system. Diabetes Care. 2004;27(1):162-167.

41. Rosenstock J, Eliaschewitz F, Heilmann C, Muchmore DB, Hayes R, Belin R. Comparison of prandial AIR inhaled insulin alone to intensified insulin glargine alone and to AIR insulin plus intensified insulin glargine in patients with type 2 diabetes previously treated with once-daily insulin glargine. Diabetes Technol Ther. 2009;11(S2) S63-S73.

42. Rosenstock J, Capelleri JC, Bolinder B, Gerber RA. Patient satisfaction and glycemic control after 1 year with inhaled insulin (Exubera) in patients with type 1 or type 2 diabetes. Diabetes Care 2004;27(6):1318-1323.

43. Ford ES, Mokdad AH, Gregg EW. Trends in cigarette smoking among US adults with diabetes: findings from the Behavioral Risk Factor Surveillance System. Prev Med. 2004;39(6):1238-1242.

44. Wise S, Chien J, Yeo K, Richardson C. Smoking enhances absorption of insulin but reduces glucodynamic effects in individuals using the Lilly-Dura inhaled insulin system. Diabet Med. 2006;23(5):510-515.

45. Himmelmann A, Jendle J, Mellén A, Petersen AH, Dahl UL, Wolmer P. The impact of smoking on inhaled insulin. Diabetes Care. 2003;26(3): 677-682.

46. Becker RH, Sha S, Frick AD, Fountaine RJ. The effect of smoking cessation and subsequent resumption on absorption of inhaled insulin. Diabetes Care. 2006;29(2):277-282.

47. Targher G, Alberiche M, Zenere MB, Bonadonna RC, Muggeo M, Bonora E. Cigarette smoking and insulin resistance in patients with noninsulin-dependent diabetes mellitus. J Clin Endocrinol Metab. 1997;82(11):3619-3624.

48. Fountaine R, Milton A, Checchio T, et al. Acute passive cigarette smoke exposure and inhaled human insulin (Exubera) pharmacokinetics. Br J Clin Pharmacol. 2008;65(6):864-870. 
49. Kling J. Inhaled insulin's last gasp? Nat Biotech. 2008;26(5):479-480.

50. McElduff A, Mather LE, Kam PC, Clauson P. Influence of acute upper respiratory tract infection on the absorption of inhaled insulin using the AERx insulin Diabetes Management System. Br J Clin Pharmacol. 2005;59(5):546-551.

51. Wolzt M, de la Pena A, Berclaz PY, Tibaldi FS, Gates JR, Muchmore DB. AIR inhaled insulin versus subcutaneous insulin: pharmacokinetics, glucodynamics and pulmonary function in asthma. Diabetes Care. 2008;31(4): 735-740.

52. Mannino DM, Thorn D, Swensen A, Holguin F. Prevalence and outcomes of diabetes, hypertension, and cardiovascular disease in COPD. Eur Respir J. 2008;32(4):962-969.

53. Rave K, de la Pena A, Tibaldi FS, et al. AIR inhaled insulin in subjects with chronic obstructive pulmonary disease. Diabetes Care. 2007;30(7):1777-1782.

54. McGrath MW, Thomson ML. The effect of age, body size and lung volume change on alveolar-capillary permeability and diffusing capacity in man. J Physiol. 1959;146(3):572-582.

55. Henry RR, Mudalier S, Chu N, et al. Young and elderly type 2 diabetic patients inhaling insulin with the AERx insulin diabetes management system: a pharmacokinetic and pharmacodynamic comparison. J Clin Pharmacol. 2003;43(11):1228-1234.

56. Skyler JS, Cefalu WT, Kourides IA, et al. Efficacy of inhaled human insulin in type 1 diabetes mellitus: a randomised proof-of-concept study. Lancet. 2001;357(9253):331-335.

57. Barnett AH, Lange P, Dreyer M, Serdarevic-Pehar M. Long-term tolerability of inhaled human insulin (Exubera) in patients with poorly controlled type 2 diabetes. Int J Clin Pract. 2007;61(10):1614-1625.

58. Davis WA, Knuiman M, Kendal P, Grange V, Davis TM. Glycemic exposure is associated with reduced pulmonary function in type 2 diabetes. The Fremantle Diabetes Study. Diabetes Care. 2004;27(3):752-757.

59. Skyler JS. Sustained long-term efficacy and safety of inhaled insulin during 4 years of continuous therapy. Diabetes. 2004;53:A115.

60. Dahl-Jørgensen K, Torjesen P, Hanssen KF, Sandvik L, Aagenaes O. Increase in insulin antibodies during continuous subcutaneous insulin infusion and multiple-injection therapy in contrast to conventional treatment. Diabetes. 1987;36(1):1-5.

61. Lassmann-Vague V, Belicar P, Raccah D, Vialettes B, Sodoyez JC, Vague P. Immunogenicity of long-term intraperitoneal insulin adminstration with implantable programmable pumps: metabolic consequences. Diabetes Care. 1995;18(4):498-503.
62. Schernthaner G. Immunogenicity and allergenic potential of animal and human insulins. Diabetes Care. 63. 1993;16(Suppl 3):155-165.

63. Walford S, Allison SP, Reeves WG. The effect of insulin antibodies on insulin dose and diabetic control. Diabetologia. 1982;22(2):106-110.

64. Peters A, Klose O, Hefty R, Keck F, Kerner W. The influence of insulin antibodies on the pharmacokinetics of NPH insulin in patients with type 1 diabetes treated with human insulin. Diabet Med. 1995;12(10):925-930.

65. Seewi O, Jaeger C, Bretzel RG, Schönau E. Insulin binding to antibodies is a risk factor for inexplicable severe hypoglycaemia in children with type-1 diabetes mellitus. Exp Clin Endocrinol Diabetes. 2008;116(5):293-297.

66. Kim MR, Sheeler LR, Mansharamani N, Haug MT, Faiman C, Gupta MK. Insulin antibodies and hypoglycemia in diabetic patients. Can a quantitiative analysis of antibody binding predict the risk of hypoglycemia? Endocrine. 1997;6(3):285-291.

67. Fineberg SE, Kawabata T, Finco-Kent D, Liu C, Krasner A. Antibody response to inhaled insulin in patients with type 1 or type 2 diabetes. J Clin Endocrinol Metab. 2005;90(6):3287-3294.

68. Wolff RK. Safety of inhaled proteins for therapeutic use. J Aerosol Med. 1998;11(4):197-219.

69. Freemantle N, Blonde L, Duhot D, et al. Availability of inhaled insulin promotes greater perceived acceptance of insulin therapy in patients with type 2 diabetes. Diabetes Care. 2005;28(2):427-428.

70. Bergenstal R, Freemantle N, Leyk M, Cutler G, Hayes R, Muchmore DB. Does availability of AIR insulin increase insulin use and improve glycemic control in patients with type 2 diabetes. Diabetes Technol Ther. 2009;11(S2): S45-S52.

71. Osterberg L, Blaschke T. Adherence to medication. $N$ Engl J Med. 2005;353(5):487-496.

72. Claxton AJ, Cramer J, Pierce C. A systematic review of the associations between dose regimens and medication compliance. Clin Ther. 2001;23(8):1296-1310.

73. Cramer JA, Okikawa J, Bellaire S, Clauson P. Compliance with inhaled insulin treatment using the AERx iDMS insulin diabetes management system. Diabetes Technol Ther. 2004;6(6):800-807.

74. Black C, Cummins E, Royle P, Philip S, Waugh N. The clinical effectiveness and cost-effectiveness of inhaled insulin in diabetes mellitus: a systematic review and economic evaluation. Health Technol Assess. 2007;11(33):1-126.
Vascular Health and Risk Management

\section{Publish your work in this journal}

Vascular Health and Risk Management is an international, peerreviewed journal of therapeutics and risk management, focusing on concise rapid reporting of clinical studies on the processes involved in the maintenance of vascular health; the monitoring, prevention and treatment of vascular disease and its sequelae; and the involvement of

\section{Dovepress}

metabolic disorders, particularly diabetes. This journal is indexed on PubMed Central and MedLine. The manuscript management system is completely online and includes a very quick and fair peer-review system, which is all easy to use. Visit http://www.dovepress.com/ testimonials.php to read real quotes from published authors. 